Research Article

\title{
Experimental Study on the Bond Performance between Fiber-Reinforced Polymer Bar and Unsaturated Polyester Resin Concrete
}

\author{
Wenchao Li $\mathbb{D},{ }^{1,2}$ Min Zhou $\mathbb{D}^{\mathbb{D}},{ }^{3}$ Fusheng Liu $\mathbb{D}^{1},{ }^{1}$ Yuzhao Jiao $\mathbb{D}^{4},{ }^{4}$ and Qingfeng Wu $\mathbb{D}^{2}$ \\ ${ }^{1}$ College of Water Conservancy and Civil Engineering, Shandong Agricultural University, Taian 271018, China \\ ${ }^{2}$ College of Mechanical and Architectural Engineering, Taishan University, Taian 271000, China \\ ${ }^{3}$ School of Science, North University of China, Taiyuan 030051, China \\ ${ }^{4}$ Shandong Safety Industrial Co., Ltd., Taian 271000, China \\ Correspondence should be addressed to Fusheng Liu; liufsh@sdau.edu.cn
}

Received 22 December 2020; Revised 14 April 2021; Accepted 21 April 2021; Published 29 April 2021

Academic Editor: Lingzhi Li

Copyright (C) 2021 Wenchao Li et al. This is an open access article distributed under the Creative Commons Attribution License, which permits unrestricted use, distribution, and reproduction in any medium, provided the original work is properly cited.

Fiber-reinforced polymer (FRP) bar-reinforced unsaturated polyester resin concrete (UPC) can solve the problem of rebar corrosion in ordinary reinforced concrete members. However, it has not been widely used in engineering practice because there have been few studies conducted on the bond behaviors of FRP bar and UPC, and the interaction mechanisms between FRP bar and UPC have not been well understood. A series of pull-out tests are conducted on FRP bar-UPC specimens to study the bond behaviors between these two materials. Parametric studies are also carried out to investigate the effects of FRP bar diameter, fiber type, type of surface treatment, concrete cover thickness, and interfacial bond length between the two. Three failure modes of the specimens are observed from pull-out tests, i.e., FRP bar pull-out, tensile failure of FRP bar, and UPC split. A new constitutive model is, therefore, proposed to predict the bond stress of FRP bar and UPC in the residual stage, and the proposed model is finally verified by test data reported in this study.

\section{Introduction}

Corrosion of steel bars in ordinary reinforced concrete structures is not uncommon in engineering practice due to the cracking and spalling of concrete cover. Fiber-reinforced polymer (FRP) bar has attracted more attention as an alternative to steel bar due to its high corrosion resistance and high tensile strength, especially in a water environment where steel bar corrosion occurs frequently $[1,2]$. On the other hand, compared with ordinary Portland cement-based concrete, unsaturated polyester resin concrete (UPC), with higher compressive strength and corrosion resistance, has been used in many construction projects such as building structure repair, road and bridge pavement repair, and machine tool bed [3, 4]. FRP bar-reinforced UPC components can completely address the engineering problem of poor corrosion resistance in ordinary reinforced concrete components. And the combination of FRP bar and UPC can realize the full potential of the high tensile strength of FRP bar and the high compressive strength of UPC, avoiding the waste of material strength. It is reported that the compressive strength of UPC can reach more than $100 \mathrm{MPa}$ [5], and the tensile strength of glass fiber-reinforced polymer (GFRP) bars can reach $1000 \mathrm{MPa}$ [6]. Additionally, both raw materials of FRP bar and UPC are made of resin to make their physical properties similar (such as the similar coefficient of thermal expansion and elastic modulus). Gorninski et al. [5] reported that UPC modulus elasticity is $29 \mathrm{GPa}$, close to the GFRP bar modulus elasticity of 35-51 GPa reported by ACI 440.1R-15 [7]. This can make FRP bar and UPC better assume external loads and more coordinated deformation. Therefore, it is in great need of the combination of FRP bar and UPC to resist external environmental erosion and load in sewage treatment engineering, ocean engineering, 
drainage pipeline engineering, and other fields. However, FRP bar-reinforced UPC structures are seldom used in engineering practice because few tests have been conducted on the bond behaviors of the FRP bar and UPC, and the interaction mechanisms between them have not been fully understood.

The bond behavior between FRP bar and ordinary concrete has been widely studied in the literature [8-14]. A series of pull-out tests were conducted by Hao et al. [8] on the effects of rib spacing and rib height of GFRP bar on the bond strength of GFRP bar and ordinary concrete. According to their report, the highest bond strength between GFRP bar and concrete was obtained when rib spacing and rib height of GFRP bar were $100 \%$ and $6 \%$, respectively, of GFRP bar diameter. Zhang et al. [9] investigated the effect of fiber surface treatment on the bond behavior between FRP bar and ordinary concrete and indicated that FRP barreinforced concrete failure could be divided into two types: rib unpeeled splitting failure and rib peeling failure. Gao et al. $[10,11]$ studied the mechanism of bond stress transfer between FRP bar and concrete by performing pull-out tests and beam tests, proposing a new design approach for calculating the bond length required between FRP bar and concrete. Baena et al. [12] and Rolland et al. [13] examined how the bond stress between FRP bar and ordinary concrete was affected by the type of surface treatment and diameter of FRP bar as well as the strength of concrete. Veljkovic et al. [14] discussed the effect of concrete cover thickness on the bond behavior of FRP bar-reinforced concrete and reported that ribbed bars possessed higher bond strength with concrete than smooth bars.

Many constitutive models have been proposed to simulate the bond stress-slippage relationship between the reinforced bar and ordinary concrete (e.g., BPE model [15], MBPE model [16], Malvar model [17], CMR model [18], and continuous curve model [19]). BPE model proposed by Eligheuaesn et al. [15] is the most widely used constitutive model for representing the bond stress-slippage relationship of steel bar-reinforced concrete due to its simple form and few fitting parameters. Cosenza et al. [16] modified the BPE model to simulate the bond stress-slippage curve of FRP barreinforced concrete. The proposed model, therefore, called "MBPE," inherited the merits of the BPE model (i.e., simple form and few parameters). However, a linear function was employed in the MBPE model to fit the residual section of the bond stress-slip curve, and significant errors were generated. The curvilinear function was introduced by Malvar [17] to simulate the bond stress-slippage curve of FRP bar-reinforced concrete. However, the proposed models contained many parameters, and the functional expressions were too complicated to be used. Cosenza et al. [18] proposed a CMR curve model, only considering the rising section of bond slip of FRP bar and concrete. The model was simple in form, fitting well with the rising section of the test with few test fitting parameters. However, the significant shortcoming of the model was that it did not consider the constitutive relationship between the falling section and the residual section, and it had limitations in the current application. A continuous curve model was proposed by Gao et al. [19], which was capable of fitting the falling section of the bond stress-slippage curve for FRP barreinforced concrete; however, a horizontal line was employed to represent the bond residual section of the bond stress-slippage curve, which was inconsistent with the fact.

The bond performance of FRP bar-reinforced special concrete has also received great attention recently [20-29]. Yang et al. [20] studied the bond behavior between basalt fiber-reinforced polymer (BFRP) bar and coral concrete with a series of pull-out tests. It was indicated that the variation of bond stress between BFRP and coral concrete with increased relative slippage could be divided into five stages (i.e., microslip stage, sliding stage, stripping stage, declining stage, and residual stage), and two failure modes were observed, i.e., BFRP bar pull-out and coral concrete split. Wu et al. [21] researched the bond behavior between GFRP bar and engineering cement-based composite (ECC) with pull-out tests, reporting that the bond strength between GFRP bar and ECC could be improved significantly by increasing rib height of GFRP bar, the thickness of ECC protective cover, and strength of ECC. Baena et al. [22] reported that the bond stress-slippage curve of FRP bar-reinforced recycled aggregate concrete was not significantly different from that of FRP bar-reinforced natural aggregate concrete. Wan et al. [23] studied the bond behavior of BFRP bar-reinforced steam-cured concrete and found that concrete strength had a significant effect on the bond strength between BFRP bar and steam-cured concrete. Zhang et al. [24] reported that the bond strength between GFRP bar and rubber concrete decreased with the increase of the diameter of GFRP bar, while it increased with the increase of the proportion of rubber substitution and the strength of rubber concrete. A theoretical formula was proposed by Chen et al. [25] for calculating the minimum bond length required between FRP bar and coral concrete. Liu et al. [26] investigated the bond strength between BFRP bar and recycled aggregate concrete (RAC) with a series of pull-out tests. The strength of RAC was found to have a more significant effect on the bond strength between the BFRP bar and RAC compared with the volume content and length of chopped basalt fiber. The longterm bond performance of BFRP bar-reinforced seawater sea-sand concrete was studied by Dong et al. [27]. It was found that the retention rate of bond strength between BFRP bar and seawater sea-sand concrete after dry-wet cycling for nine months was $92 \%$, higher than that (i.e., $78 \%$ ) after water immersion. Nemeth et al. [28] reported that the bond strength between smooth steel bar and polymer concrete was as much as 10 times higher than that between steel bar and ordinary concrete. Douba et al. [29] found that the bond strength between steel bar and polymer concrete could be significantly improved by adding aluminum nanoparticles in polymer concrete.

Totally, 27 pull-out tests on FRP bar-UPC specimens have been conducted and are reported in this paper. The objectives of the work are as follows: (1) measuring bond behaviors of FRP bar and UPC to investigate the interaction mechanisms between the two materials, (2) monitoring and interpreting the failure modes of FRP bar-reinforced UPC specimens, and (3) developing a constitutive model to 
predict the residual bond stress between FRP bar and UPC. The test data from this project can be of great value in explaining how FRP bar and UPC work together to resist external tensile force and in providing physical evidence for promoting engineering application of FRP bar-reinforced UPC structures.

\section{Experimental Program}

\subsection{Test Materials}

2.1.1. UPC Raw Materials. Quartz sand from Huarong Quartz Sand Factory in Tai' an City is used as UPC aggregate in the tests. The particle size of the quartz sand is from 120 mesh to 20 mesh and from $3 \mathrm{~mm}$ to $5 \mathrm{~mm}$, as shown in Figure 1. A type of unsaturated polyester resin, "9611," is used, which is a linear polymer formed by saturated dibasic acid, unsaturated dibasic acid, and diol. V388-type Hardener and KH570 coupling agent are used, and the dosages are 1\% and 1.5\%, respectively, of 9611-type resin amount. The hardener can cure the resin at room temperature, and the coupling agent can improve the surface bonding properties between resin and aggregate.

2.1.2. Mechanical Properties of UPC. According to mixing ratios tabulated in Table 1, six cube UPC specimens of size $150 \mathrm{~mm} \times 150 \mathrm{~mm} \times 150 \mathrm{~mm}$ are prepared with the following steps: (1) the hardener and coupling agent are firstly added to the resin solvent; (2) the mixed solution is stirred until it becomes milky white, and the quartz sand is then added; (3) the prepared UPC slurry is poured into cube molds, and 1 day later, the specimens are dismantled from the molds and cured at room temperature $\left(25^{\circ} \mathrm{C}\right)$ for 7 days. After the specimen has been produced as shown in Figure 2, unconfined compressive strength and splitting tensile strength tests are conducted on the UPC specimens. Test results show that the average value of unconfined compressive strength of the UPC specimens is $98.22 \mathrm{MPa}$, and that of splitting tensile strength is $4.97 \mathrm{MPa}$.

2.1.3. Mechanical Properties of FRP Bars. In the tests, FRP bars produced by Shandong Safety Industrial Co., Ltd., are used, mainly composed of vinyl resin and alkali-resistant fibers, including ribbed GFRP bars with diameters of 6,10 , and $15 \mathrm{~mm}$ (denoted as R-GFRP-6, R-GFRP-10, and R-GFRP-15), sandblasted ribbed GFRP bars with a diameter of $10 \mathrm{~mm}$ (SR-GFRP-10), and ribbed BFRP bars with a diameter of $10 \mathrm{~mm}$ (R-BFRP-10), as shown in Figure 3. Values of tensile strength, tensile modulus, and elongation of the test bars are listed in Table 2.

2.1.4. FRP Bar-UPC Specimen Preparation. Procedures adopted in the tests are as follows:

(1) A pair of holes are machined at opposing sidewalls of detachable cube molds of size $150 \mathrm{~mm} \times 150 \mathrm{~mm} \times 150 \mathrm{~mm}$ to pass through FRP bars of a certain length. Some portion of the FRP bar is enclosed in a PVC tube to vary the bonding length between the bar and UPC, and hot melt glue is applied to seal the connection of the PVC tube and the plastic mold

(2) The prepared UPC slurry is poured into the cube mold and vibrated on a vibrating table for 20 minutes. After 24 hours of curing, the FRP barreinforced UPC specimen is dismantled from the mold

(3) A steel tube is used to enclose the FRP bar at the load anchor end (Figure 4) to prevent the FRP bar from any damage during the test, and high-strength concrete grout is used to anchor the steel tube and FRP bar

2.2. Test Apparatus and Method. The WAW-1000D electrohydraulic servo universal testing machine is used in this study, with a range of $10-1000 \mathrm{kN}$ and an accuracy of $0.05 \mathrm{kN}$. A self-made frame is employed to apply drawing loads on the specimens, as shown in Figure 5. Two displacement gauges are used to monitor the relative slippage between FRP bar and UPC, with a range and accuracy of $50 \mathrm{~mm}$ and $0.001 \mathrm{~mm}$, respectively. Test data are recorded automatically at a time interval of 1 second. According to CSA S807:19 [6], the loading rate is set to $1 \mathrm{~mm} / \mathrm{min}$. The test is terminated when one of the following conditions is met: (a) local tensile cracks appear on FRP bar, (b) UPC split occurs, (c) FRP bar is pulled out from UPC, or (d) the relative slippage between the FRP bar and UPC concrete is up to $20 \mathrm{~mm}$.

\section{Test Results and Analysis}

3.1. Test Results. Three failure modes of FRP bar-UPC specimens (i.e., FRP bar pull-out, tensile failure of FRP bar, and UPC split) are observed during the pull-out tests. Among them, the tensile failure of the FRP bar is special, which has rarely found in the pull-out tests of ordinary concrete with FRP bars. This is attributed to the fact that the bond strength between FRP bar and UPC is much higher than that between FRP bar and ordinary concrete. With SRGFRP-10- 5D-C70 as an example, its average bond strength is $41.98 \mathrm{MPa}, 2.28$ times higher than that of GFRP bar-ordinary concrete specimens of the same size (18.39 MPa) [30]. It is because that UPC has greater strength than ordinary concrete and the use of resin as cementing material produces stronger interfacial adhesion with FRP bar which is also resin-based. The influence of each factor on bond strength will be analyzed in detail. The three failure forms are shown in Figure 6. It is seen from Figure 6(a) that the anchorage section of the ribbed FRP bar is seriously worn, and some ribs are completely worn out. A large amount of FRP bar residues is left on the surface of UPC. Figure 6(b) shows that tensile cracks are formed in the nonanchorage section. It is also found that the surface sandblasting of the anchorage section of FRP bars is worn. The UPC split failure features sudden cracking of UPC block, with a small amount of FRP 


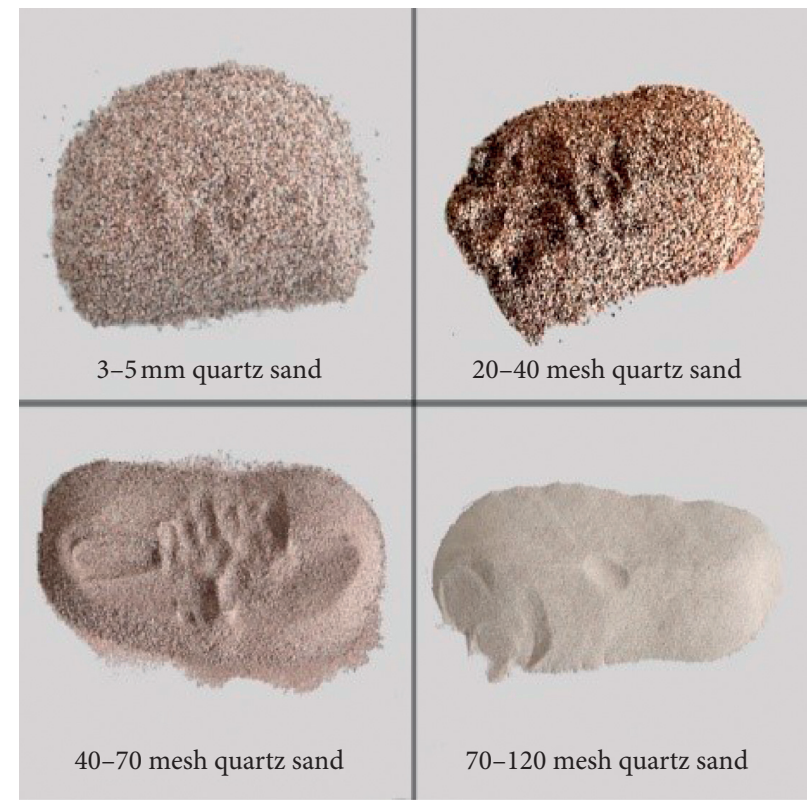

FIgURE 1: UPC aggregate.

TABLE 1: Mixing ratios of the UPC specimen.

\begin{tabular}{lcccccc}
\hline Resin & $\begin{array}{c}3-5 \mathrm{~mm} \text { quartz } \\
\text { sand }\end{array}$ & $\begin{array}{c}20-40 \text { mesh quartz } \\
\text { sand }\end{array}$ & $\begin{array}{c}40-70 \text { mesh quartz } \\
\text { sand }\end{array}$ & $\begin{array}{c}70-120 \text { mesh quartz } \\
\text { sand }\end{array}$ & $\begin{array}{c}\text { Hardener } \\
(\%)\end{array}$ & $\begin{array}{c}\text { Coupling agent } \\
(\%)\end{array}$ \\
\hline 1 & 2.829 & 1.886 & 0.943 & 0.629 & 1.5 & 1.5 \\
\hline
\end{tabular}

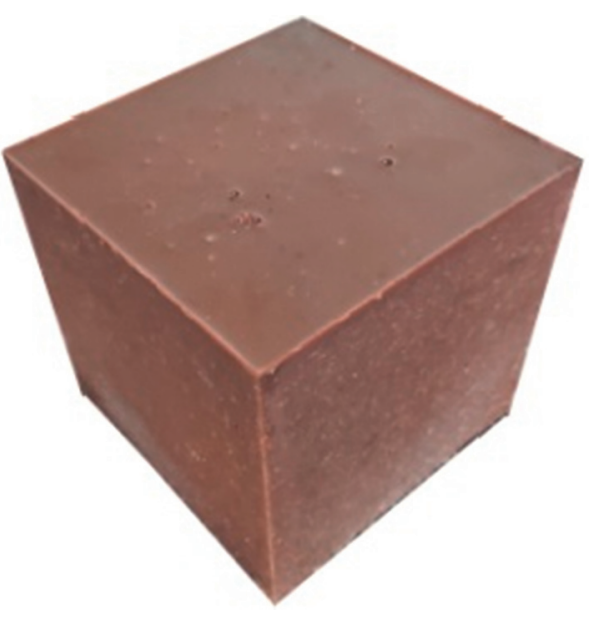

Figure 2: UPC test block.

bar residues left on the surface of UPC, as is shown in Figure 6(c).

The bond strength between FRP bar and UPC is calculated using equation (1). It is assumed that the bond stress is uniformly distributed along the bond length at the FRP bar-UPC interface.

$$
\tau=\frac{P}{\pi D L}
$$

where $\tau$ is the bond strength between FRP bar and UPC $(\mathrm{MPa}), P$ is the drawing load $(\mathrm{N}), D$ is the diameter of FRP bar ( $\mathrm{mm})$, and $L$ is the bond length between FRP bar and UPC (mm). The measured maximum drawing load and relative slippage together with the calculated bond strength are tabulated in Table 3.

\subsection{Test Results Analysis}

3.2.1. Influence of the Diameter of FRP Bar on Bond Strength. Figure 7(a) shows that bond strength between GFRP bar and UPC for R-GFRP-6-5D-C70 is $45.71 \mathrm{MPa}, 39.23 \%$ and $43.69 \%$ greater than those for R-GFRP-10-5D-C70 and R-GFRP-15-5D-C70 (31.84 MPa and $32.83 \mathrm{MPa}$, respectively). This is attributed to the fact that the bond stress between the GFRP bar and UPC becomes increasingly nonuniform with the increase of GFRP bar diameter, which is called the "shear-lag effect."

3.2.2. Influence of the Surface Shape of FRP Bar on Bond Strength. Figure 7(b) shows that the bond strength between sandblasted ribbed GFRP bar and UPC for SR-GFRP-10$5 \mathrm{D}-\mathrm{C} 70$ is $41.98 \mathrm{MPa}, 31.85 \%$ higher than that between ribbed GFRP bar and UPC for R-GFRP-10-5D-C70 $(31.84 \mathrm{MPa})$. This is because the interface friction between the GFRB bar and UPC is significantly enhanced by sandblasting surface treatment.

3.2.3. Influence of the Type of FRP Bar on Bond Strength. The bond strength between the BFRP bar and UPC for R-BFRP-10-5D-C70 (42.17 MPa) is $32.44 \%$ higher than that 


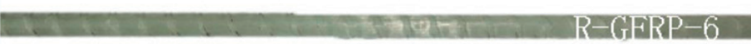

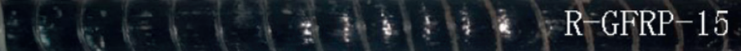

\section{$\mathrm{R}-\mathrm{BFRP}-10$}

Figure 3: FRP bars used in the test.

TABle 2: Properties of FRP.

\begin{tabular}{lccc}
\hline & Tensile strength $(\mathrm{MPa})$ & Tensile modulus $(\mathrm{GPa})$ & Elongation $(\%)$ \\
\hline R-GFRP-6 & 1181.15 & 55.70 & 2.02 \\
R-GFRP-10 & 1016.10 & 53.85 & 2.03 \\
R-GFRP-15 & 987.15 & 53.30 & 1.92 \\
SR-GFRP-10 & 1116.30 & 54.25 & 2.19 \\
R-BFRP-10 & 1194.95 & 61.3 & 2.84 \\
\hline
\end{tabular}

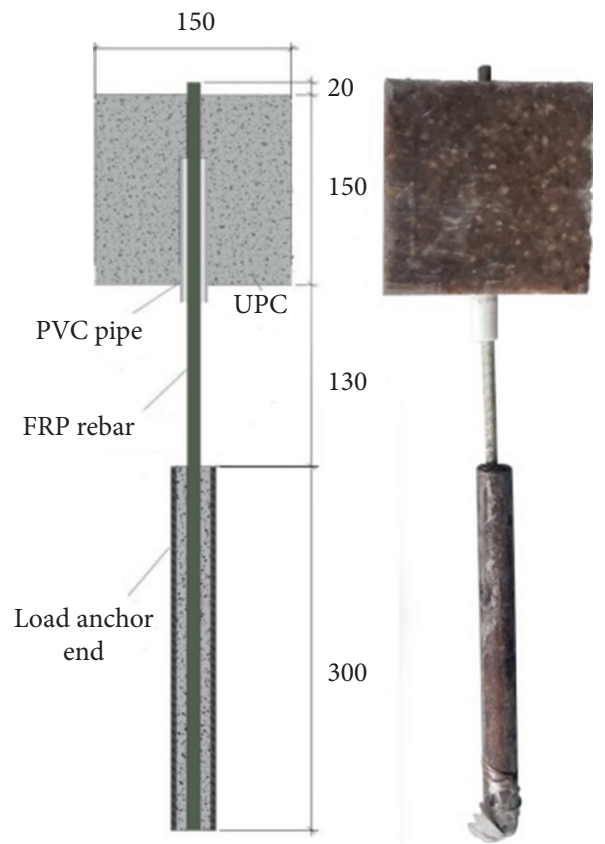

FIgURE 4: FRP bar-UPC specimen.

for R-GFRP-10-5D-C70 (31.84 MPa), as shown in Figure 7 (c). The possible reason is that basalt fiber has better bonding performance with polyester resin compared to glass fiber.

3.2.4. Influence of the Thickness of Concrete Cover Layer on Bond Strength. It is seen from Figure $7(\mathrm{~d})$ that bond strength between GFRP bar and UPC for R-GFRP-10-5D-
$\mathrm{C} 70$ is $31.84 \mathrm{MPa}, 10.03 \%$ and $0.44 \%$ greater than those for R-GFRP-10-5D-C30 and R-GFRP-10-5D-C50 (28.81 MPa and $31.70 \mathrm{MPa}$, respectively). It is indicated that the bond strength between the GFRP bar and UPC increases with the increase of concrete cover thickness. This phenomenon is mainly due to the oblique pressure generated by the extrusion of the ribbed bar and concrete, and the force along the radial component is balanced by the concrete tensile stress around the FRP bar. When the thickness of the 


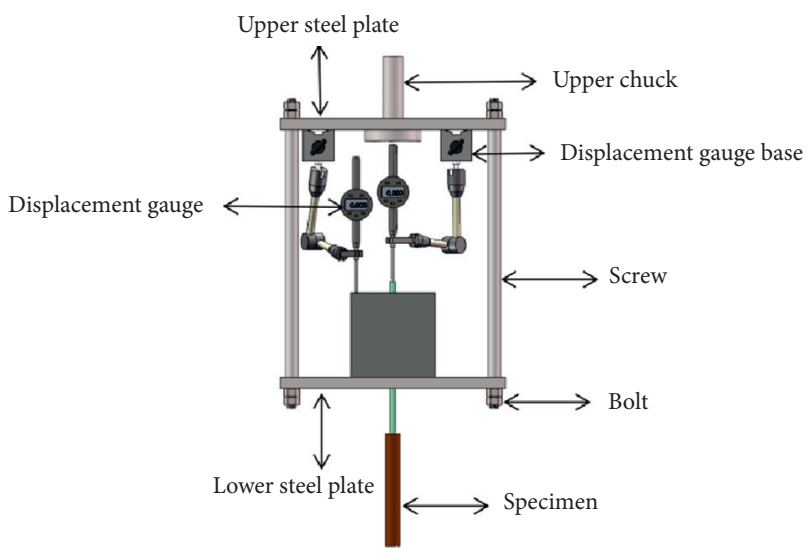

(a)

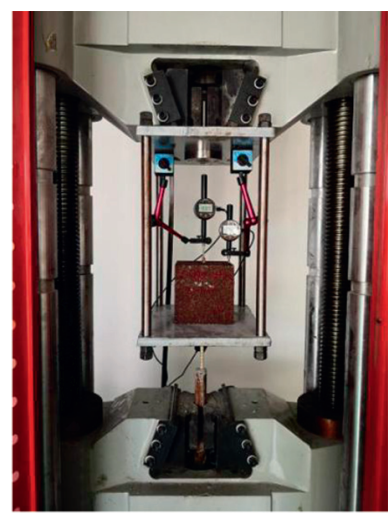

(b)

Figure 5: Self-made device for the pull-out test. (a) Schematic diagram. (b) Photo.

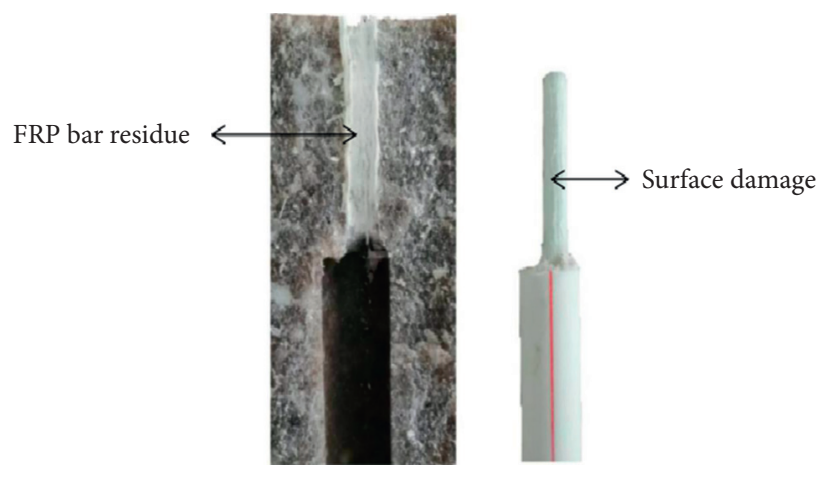

(a)

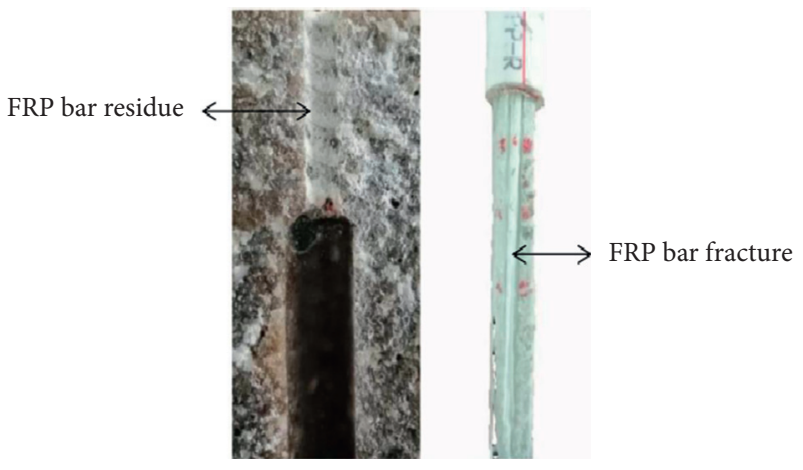

(b)
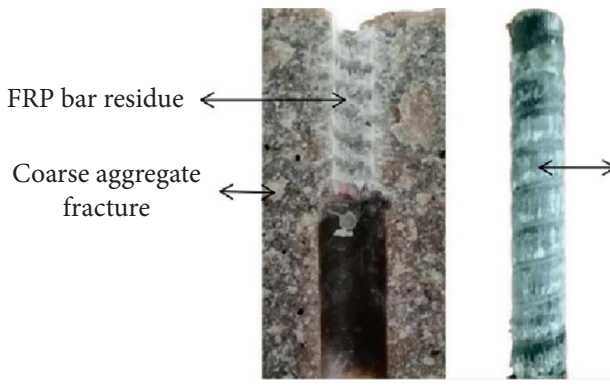

Slight surface

damage

(c)

FIGURE 6: Failure mode of specimens. (a) FRP bar pull-out. (b) Tensile fracture of FRP bar. (c) UPC split.

concrete cover is small, the radial component force transmission path is reduced, and the bonding strength is reduced. When the thickness of the concrete cover reaches a certain value, the increase in bond strength decreases. Under this thickness of the concrete cover, the radial component force can be fully balanced.

3.2.5. Influence of the Bond Length on Bond Strength. Figure 7(e) shows that the bond strength between GFRP bar and UPC for R-GFRP-10-3D-C70 is 35.99 MPa, respectively, $13.03 \%$ and $26.5 \%$ greater than those for R-GFRP-10-5DC70 and R-GFRP-10-7D-C70 (31.84 MPa and 28.45 MPa).
This indicates that the bond strength between FRP bar and UPC decreases with an increase of bond length, due to the fact that the greater the bond length between GFRP bar and UPC is, the more serious nonuniformity of the bond stress is.

\section{Relationship of Bond Stress and Slippage at FRP Bar-UPC Interface}

4.1. Test Specimens with Occurrence of FRP Bar Pull-Out Failure. Figure 8 shows the variation of the bond stress between FRP bar and UPC with increased relative slippage. It is seen that the bond stress-slippage curves can be divided 
TABLE 3: Summary of FRP bar-UPC pull-out bond test results.

\begin{tabular}{|c|c|c|c|c|c|c|c|}
\hline Specimen number & $F_{\max }(\mathrm{kN})$ & $\bar{F}_{\max }(\mathrm{kN})$ & $\tau_{\max }(\mathrm{MPa})$ & $\bar{\tau}_{\text {max }}(\mathrm{MPa})$ & $S_{r}(\mathrm{~mm})$ & $\bar{S}_{r}(\mathrm{~mm})$ & Failure mode \\
\hline \multirow{3}{*}{ R-GFRP-10-5D-C70* } & 52.70 & \multirow{3}{*}{49.98} & 33.57 & \multirow{3}{*}{31.84} & 1.18 & \multirow{3}{*}{1.06} & Pull-out \\
\hline & 46.50 & & 29.62 & & 0.92 & & Pull-out \\
\hline & 50.75 & & 32.32 & & 1.08 & & Pull-out \\
\hline \multirow{3}{*}{ SR-GFRP-10-5D-C70 } & 68.35 & \multirow{3}{*}{65.90} & 43.54 & \multirow{3}{*}{41.98} & 0.82 & \multirow{3}{*}{0.99} & Rebar fracture \\
\hline & 66.45 & & 42.33 & & 1.27 & & Rebar fracture \\
\hline & 62.90 & & 40.06 & & 0.89 & & Rebar fracture \\
\hline \multirow{3}{*}{ R-GFRP-6-5D-C70 } & 26.45 & \multirow{3}{*}{25.84} & 46.80 & \multirow{3}{*}{45.71} & 1.65 & \multirow{3}{*}{1.81} & Pull-out \\
\hline & 25.30 & & 44.76 & & 2.04 & & Pull-out \\
\hline & 25.75 & & 45.58 & & 1.73 & & Pull-out \\
\hline \multirow{3}{*}{ R-GFRP-15-5D-C70 } & 128.05 & \multirow{3}{*}{115.98} & 36.25 & \multirow{3}{*}{32.83} & 4.21 & \multirow{3}{*}{2.73} & UPC split \\
\hline & 116.25 & & 32.91 & & 3.43 & & Pull-out \\
\hline & 103.65 & & 29.34 & & 0.55 & & Rebar fracture \\
\hline \multirow{3}{*}{ R-GFRP-10-3D-C70 } & 37.35 & \multirow{3}{*}{33.90} & 39.65 & \multirow{3}{*}{35.99} & 0.32 & \multirow{3}{*}{0.27} & Pull-out \\
\hline & 30.60 & & 32.48 & & 0.28 & & Pull-out \\
\hline & 33.75 & & 35.83 & & 0.22 & & Pull-out \\
\hline \multirow{3}{*}{ R-GFRP-10-7D-C70 } & 60.65 & \multirow{3}{*}{62.53} & 27.59 & \multirow{3}{*}{28.45} & 0.66 & \multirow{3}{*}{0.54} & Pull-out \\
\hline & 65.65 & & 29.87 & & 0.46 & & Rebar fracture \\
\hline & 61.30 & & 27.89 & & 0.51 & & Rebar fracture \\
\hline \multirow{3}{*}{ R-GFRP-10-5D-C50 } & 51.05 & \multirow{3}{*}{49.77} & 32.52 & \multirow{3}{*}{31.70} & 0.55 & \multirow{3}{*}{0.58} & Pull-out \\
\hline & 47.95 & & 30.54 & & 0.55 & & Pull-out \\
\hline & 50.30 & & 32.04 & & 0.65 & & Pull-out \\
\hline \multirow{3}{*}{ R-GFRP-10-5D-C30 } & 45.05 & \multirow{3}{*}{45.23} & 28.69 & & 1.05 & \multirow{3}{*}{1.02} & Pull-out \\
\hline & 42.45 & & 27.04 & 28.81 & 0.89 & & Pull-out \\
\hline & 48.20 & & 30.70 & & 1.12 & & Pull-out \\
\hline & 67.30 & & 42.87 & & 0.83 & & Rebar fracture \\
\hline R-BFRP-10-5D-C70 & 64.50 & 66.20 & 41.08 & 42.17 & 0.76 & 0.81 & Rebar fracture \\
\hline & 66.80 & & 42.55 & & 0.85 & & Rebar fracture \\
\hline
\end{tabular}

$F_{\max }:$ maximum bond force; $\bar{F}_{\max }$ : average maximum bond force; $\tau_{\max }:$ maximum bond strength; $\bar{\tau}_{\max }:$ average maximum bond strength; $s_{r}:$ relative slippage; $\bar{s}_{r}$ : average relative slippage. ${ }^{*} 5 \mathrm{D}$ denotes that the bond length between FRP bar and UPC was 5 times the diameter of the FRP bar and C70 denotes that the concrete cover thickness was $70 \mathrm{~mm}$.

into three phases, namely, rising stage, falling stage, and bond residual stage.

4.1.1. Rising Stage. In this stage, the bond stress between GFRP and UPC increases almost linearly with increased relative slippage. The relative slip between reinforcement and concrete at the free end is close to zero at the beginning of the test loading, bond stress increases rapidly, and the slope of the curve tends to infinity. When the tensile load is higher than the chemical bonding force, the growth of bond stress slows down, the relative slip between reinforcement and concrete occurs, and the slope of the curve decreases gradually. The bond stress between reinforcement and concrete is mainly provided by the chemical cementing force and the oblique force generated by the mutual extrusion of these two materials. The radial component of the oblique force produces frictional resistance which depends on the friction coefficient between reinforcement and concrete and the shrinkage of concrete. The longitudinal component of oblique force is the mechanical bite force between reinforcement and concrete, and the magnitude is related to FRP rib strength, concrete shear strength, and some other factors.

4.1.2. Falling Stage. A significant decline of the bond stress between the GFRP bar and UPC is observed in the falling stage with increased relative slippage, indicating that the failure of the test specimens has occurred. This can be explained as follows: after the ribs of the FRP bar are damaged or the concrete between the two ribs of the FRP bar is sheared, the mechanical bite force decreases rapidly, so that the bond strength decreases, and the relative slip between bar and concrete increases rapidly. Most of the specimens in this test exhibit shear failure of ribs of the FRP bar which is mainly related to the higher shear strength of resin concrete compared with ordinary concrete.

4.1.3. Bond Residual Stage. The bond stress between the GFRP bar and UPC fluctuates significantly with increased relative slippage in this stage, and it is mainly the friction between the surface damaged FRP bar and concrete.

\subsection{Test Specimens with Occurrence of Tensile Failure of FRP} Bar. Tensile failure of FRP bars occurs when pull-out tests are conducted on SR-GFRP-10-5D-C70 and R-BFRP-105D-C70. The bond stress-slippage curves of these two test specimens are shown in Figure 9.

It is seen that for FRP bar-reinforced UPC specimens with tensile failure of FRP bar, maximum bond slippage between FRP bar and UPC is only $1.8-2.5 \mathrm{~mm}$, with the rising stage similar to that of specimens with FRP bar pull- 


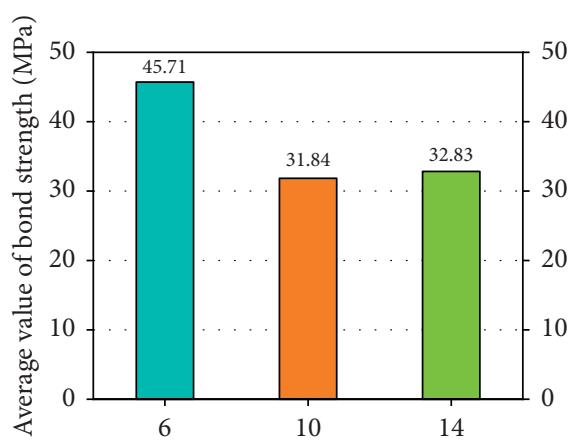

(a)

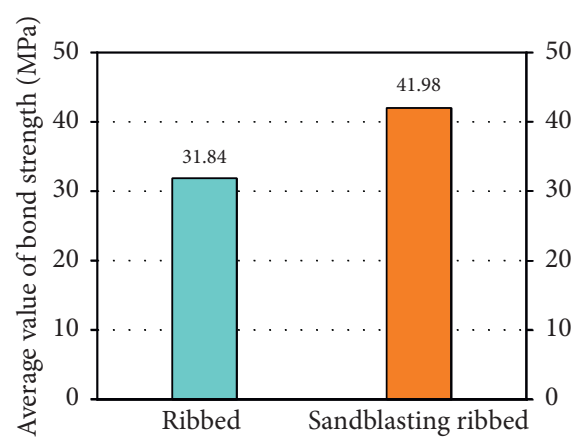

(c)

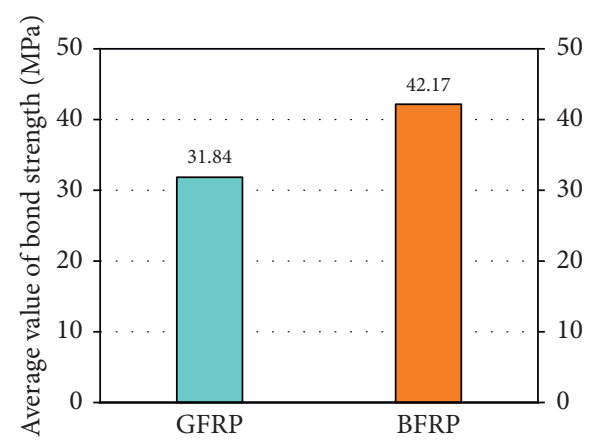

(b)

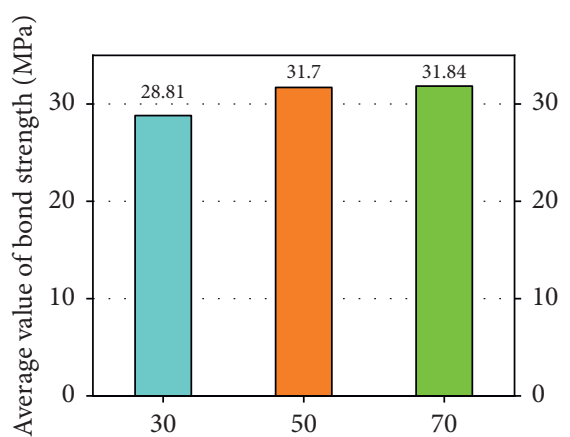

(d)

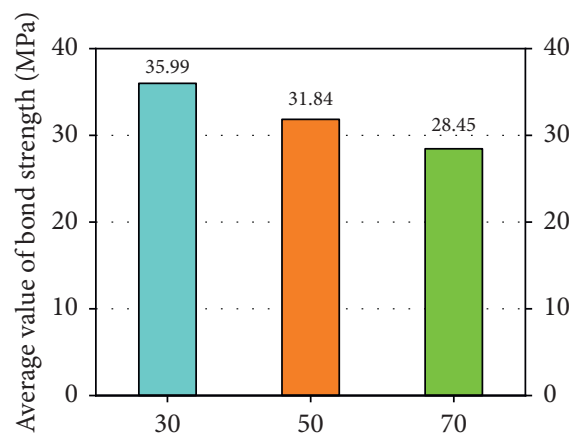

(e)

Figure 7: Influence of various factors on bond strength. (a) Diameter (mm). (b) Reinforcement type. (c) Surface shape. (d) Thickness of concrete cover (mm). (e) Bond length ( $\mathrm{mm})$.

out failure occurring. The bond stress decreases rapidly after the rising stage, and the main reason is that the fracture of reinforcement cuts off the force transmission path. This type of failure usually occurs in specimens with high bond strength.

4.3. Test Specimens with Occurrence of UPC Split Failure. UPC split failure is only observed when R-GFRP-15-5D-C70 is tested. The relationship of bond stress and slippage at the FRP bar-UPC interface is presented in Figure 10. It is seen that the bond stress increases rapidly with increased relative slippage in the rising stage and decreases dramatically after UPC split failure occurs.

The higher tensile strength of UPC than ordinary concrete is the reason for the rare occurrence of UPC split failure; however, the thickness of the UPC protective layer should be large enough to avoid this type of failure, especially when the FRP bars with a larger diameter are used because this kind of failure occurs when the concrete protective layer is too thin to transfer the oblique force generated by the extrusion of the FRP bar and concrete.

\section{Constitutive Model of FRP Bar-UPC}

The MBPE model [13] and continuous curve model [16] are the most widely used constitutive models to represent the relationship of bond stress and slippage at the FRP barconcrete interface.

The MBPE model is expressed as follows:

Rising stage: $\tau / \tau_{1}=\left(s / s_{1}\right)^{\alpha}, \quad s \leq s_{1}$

Falling stage : $\tau / \tau_{1}=1-p\left(s / s_{1}-t 1\right), \quad s_{1} \leq s \leq s_{3}$

Residual section : $\tau=\tau_{3}, \quad s \geq s_{3}$ 


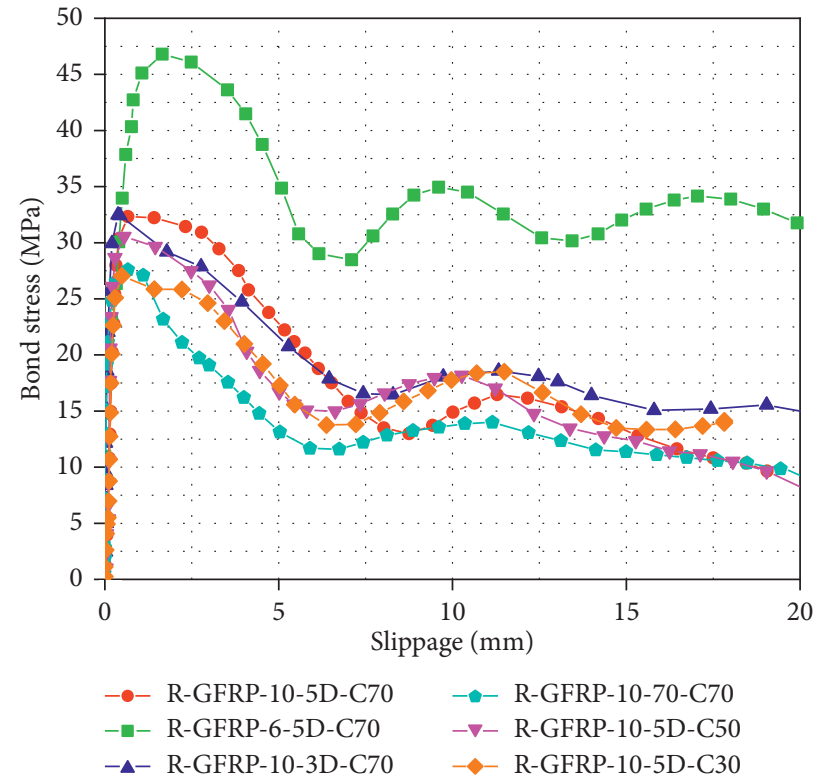

Figure 8: Bond-slip curve of pull-out failure specimen.

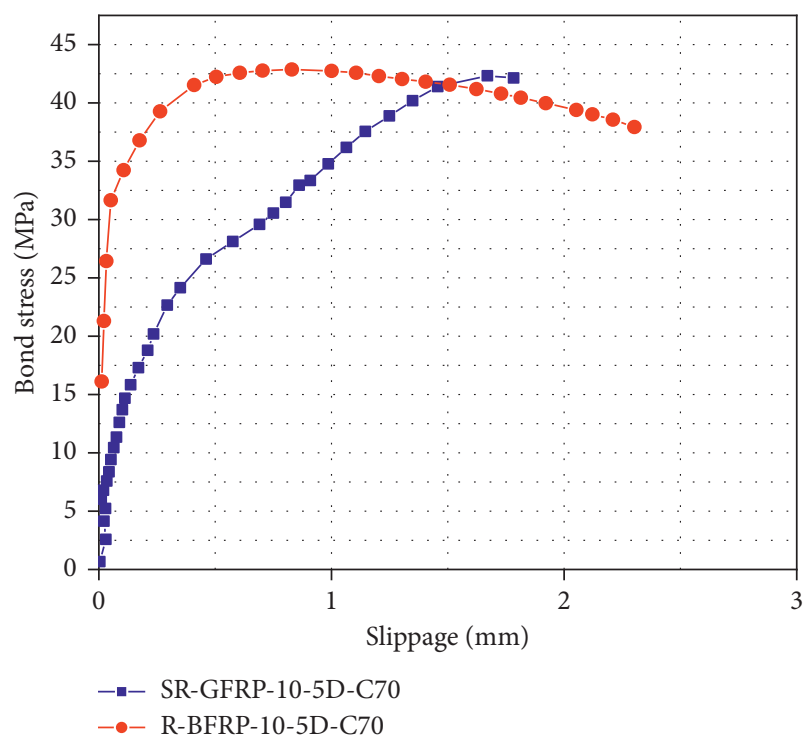

FIgURE 9: Bond-slip curve of FRP bar fracture failure specimen.

Here, $\alpha$ and $p$ are the test fitting parameters, and the meanings of other parameters are shown in Figure 11.

The parameters $\alpha$ and $p$ in the expression of MBPE constitutive relation can be obtained from test and theoretical curves of the rising stage and the falling stage, respectively, assuming that areas under these two curves are equal. The rising stage area $A_{1}$ is expressed as follows:

$$
\begin{aligned}
A_{1} & =\int_{0}^{s_{1}} \tau(s) \cdot \mathrm{d} s=\int_{0}^{s_{1}} \tau_{1} \cdot\left(\frac{s}{s_{1}}\right)^{\alpha} \cdot \mathrm{d} s=\frac{\tau_{1} \cdot s_{1}}{1+\alpha}, \\
\alpha & =\frac{\tau_{1} \cdot s_{1}}{A_{1}}-1 .
\end{aligned}
$$

The area of the falling stage is recorded as $A_{2}$ and the expression is as follows:

$$
\begin{aligned}
A_{2} & =\int_{s_{1}}^{s_{3}} \tau(s) \cdot \mathrm{d} s=\int_{s_{1}}^{s_{3}} \tau_{1}-p \tau_{1}\left(s / s_{1}-t 1\right) \mathrm{d} s \\
& =\tau_{1}(1+p)\left(s_{3}-s_{1}\right)-\frac{\tau_{1} p}{2 s_{1}}\left(s_{3}^{2}-s_{1}^{2}\right), \\
p & =\frac{2 s_{1}\left[\tau_{1}\left(s_{3}-s_{1}\right)-A_{2}\right]}{\tau_{1}\left(s_{3}-s_{1}\right)^{2}} .
\end{aligned}
$$

Based on the analysis of the test data of R-GFRP-10-5DC70 specimens, the bond-slip constitutive relation of GFRP bar-UPC based on the MBPE model is obtained as follows:

$$
\begin{aligned}
& \text { Rising stage : } \tau / \tau_{1}=\left(s / s_{1}\right)^{0.24}, \quad s \leq s_{1} \\
& \text { Falling stage : } \tau / \tau_{1}=1-0.08\left(s / s_{1}-t 1\right), \quad s_{1} \leq s \leq s_{3} \\
& \text { Residual section : } \tau=\tau_{3}, \quad s \geq s_{3}
\end{aligned}
$$

Bond stress-slippage curves obtained from this study are compared with those predicted by the MBPE model and continuous curve model, as shown in Figure 12. It is seen that the rising and falling stages are well fitted by MBPE and continuous curve models; however, significant errors are found when these two models are used to fit the residual stage.

A new constitutive model is proposed to predict the bond stress of FRP bar and UPC in the residual stage of the bond stress-slippage curve, as follows:

$$
\tau=\tau_{3}+\frac{\Delta \tau}{2}+\frac{\Delta \tau}{2} \sin \left[\frac{2 \pi}{\Delta s}\left(s-s_{3}-\frac{\Delta s}{4}\right)\right],
$$

where $\tau_{3}$ and $s_{3}$ are, respectively, the bond stress and relative slippage at the end of the falling stage, and $\Delta \tau$ and $\Delta s$ are, 


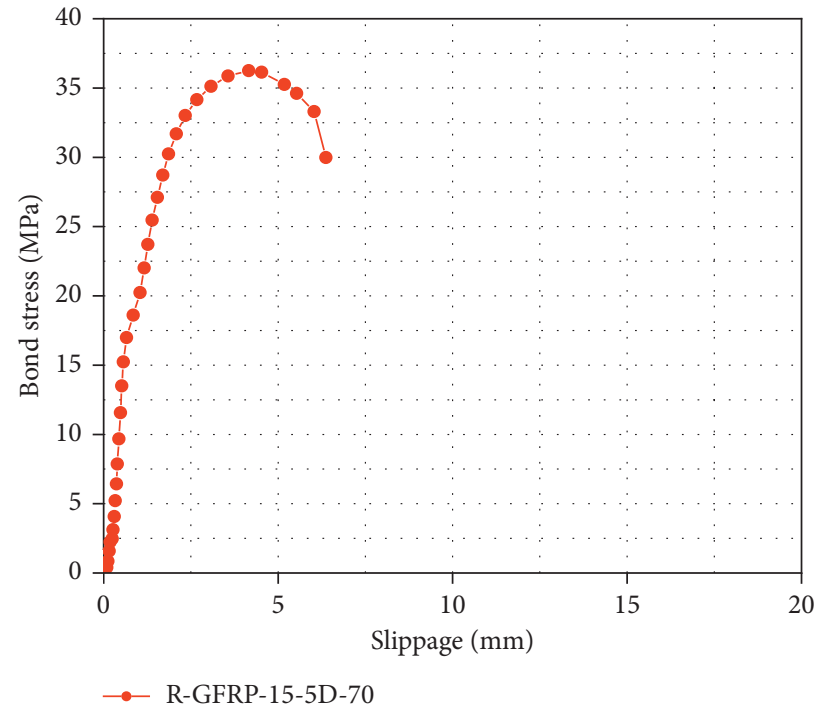

FIgURE 10: Bond-slip curve of UPC split failure specimen.

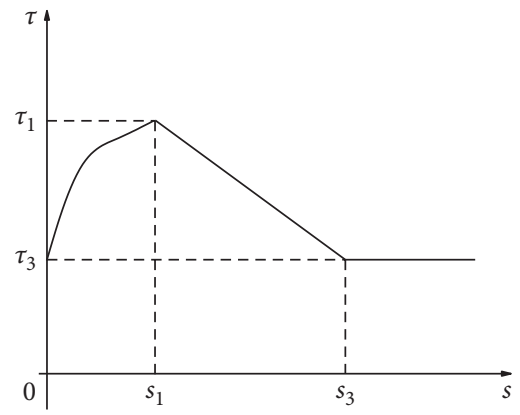

Figure 11: MBPE model [13].

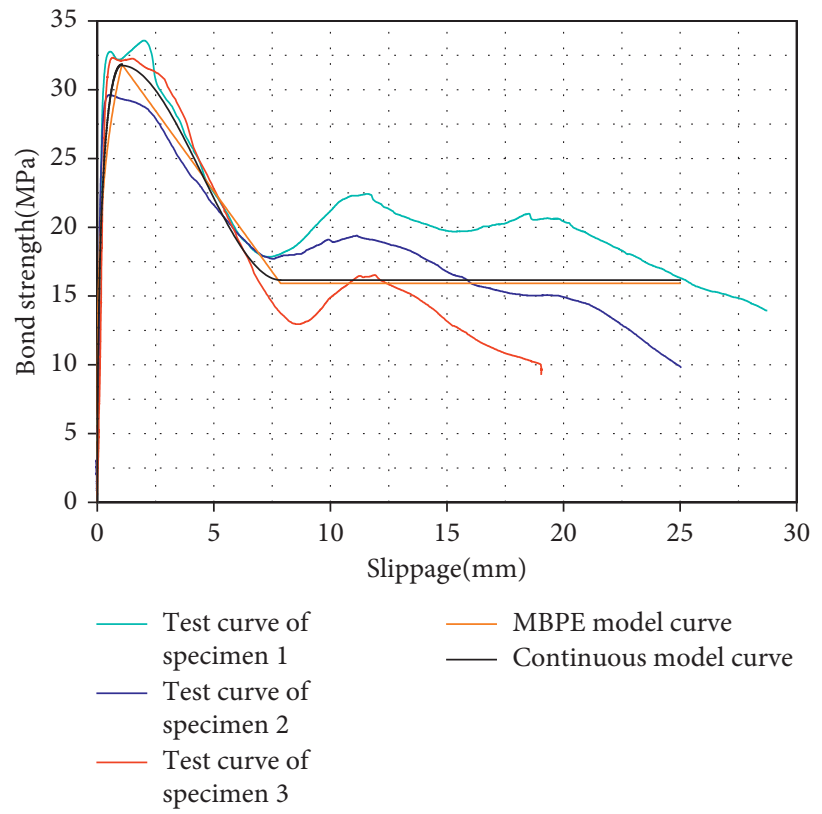

Figure 12: Comparison of the theoretical curve and experimental curve. 


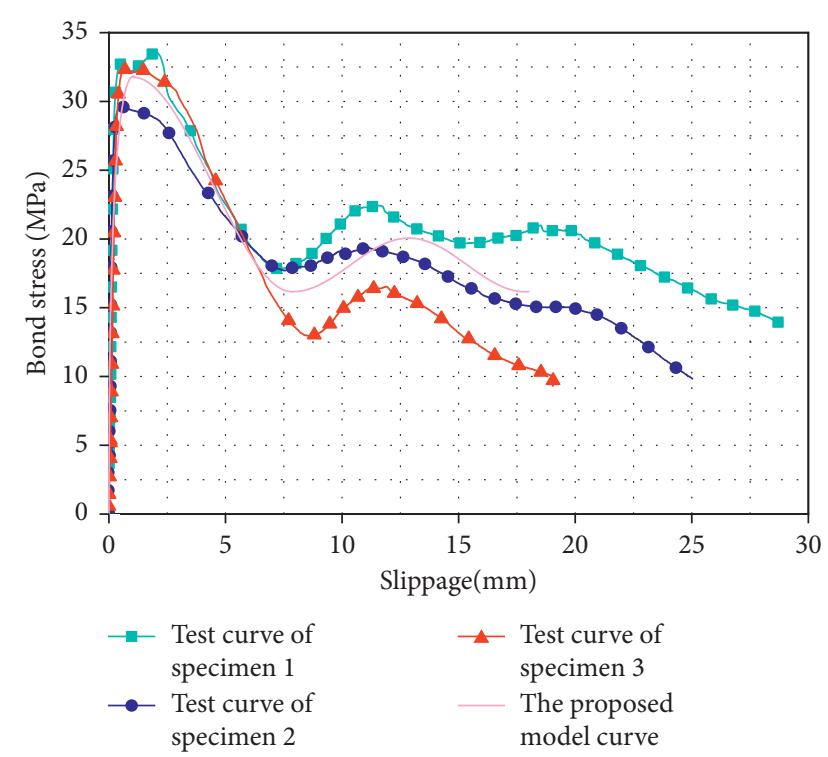

Figure 13: Comparison of test curve and proposed model curve.

respectively, the amplitude of bond stress fluctuation and the increment of relative slippage in the bond residual stage.

Figure 13 shows a comparison of the bond stress-slippage curves measured in this study and those predicted by the proposed constitutive model. It is seen that the pattern of bond stress-slippage curves in the residual stage measured in this study is well fitted by the proposed constitutive model.

\section{Conclusion}

In this paper, a series of pull-out tests are conducted on 27 FRP bar-UPC specimens. The effects of FRP bar diameter, fiber type, type of surface treatment, concrete cover thickness, and bond length at the FRP bar-UPC interface on the bond behaviors between FRP bar and UPC are investigated. The following conclusions can be drawn:

(1) Three failure modes of FRP bar-reinforced UPC specimens are observed from the pull-out tests, i.e., FRP bar pull-out, tensile failure of FRP bar, and UPC split. The failure types of FRP bar-UPC specimens depend on the interface bond stress, UPC tensile stress, and stress of the FRP bar. When the diameter of the FRP bar is small and the bond length between the FRP bar and UPC is short, it is easy for the FRP bar to pull out from the UPC because the interface bond stress between these two is beyond the bond strength. The tensile failure of the FRP bar occurs when the surface sandblasting FRP bar-reinforced specimens are tested. This is because the bond strength between the surface sandblasting FRP bar and UPC is greater than the tensile strength of the FRP bar. UPC splitting failure occurs when the tensile stress of the UPC reaches its tensile strength

(2) The FRP bar-UPC bond strength decreases with the increase of the diameter of the FRP bar due to the shear-lag effect. The larger the bond length is, the more uneven the bond stress distribution will be, which will reduce the bond strength. Additionally, the increase in the thickness of the protective layer provides greater resistance to get bond strength to increase. And surface sandblasting can increase the interface bite force, thus increasing the bond strength

(3) The bond stress-slippage curve of FRP bar-reinforced UPC can be divided into three phases, i.e., rising stage, falling stage, and bond residual stage. It is found that the rising and falling stages are well fitted by MBPE and continuous curve models; however, significant errors are produced when these two models are used to fit the residual stage

(4) A new constitutive model with few parameters and simple expression is proposed in this study to predict the bond stress between FRP bar and UPC in the residual stage. It is found that the pattern of bond stress-slippage curves in the residual stage can be well captured by the proposed model

\section{Data Availability}

The data used to support the findings of this study are included within the article.

\section{Conflicts of Interest}

The authors declare that there are no conflicts of interest regarding the publication of this paper.

\section{Acknowledgments}

This research was funded by the Key R\&D Program of Shandong Province (International Scientific and Technological Cooperation), under grant no. 2019GHZ015. The second author is grateful to the Applied Basic Research Program of Shanxi Province of China (Grant no. 201901D211209) and the Natural Science Research Foundation of North University of China (Grant no. XJJ201902).

\section{References}

[1] T.Q. Liu, X. Liu, and P. Feng, “A comprehensive review on mechanical properties of pultruded FRP composites subjected to long-term environmental effects," Composites Part B: Engineering, vol. 191, pp. 1-57, 2020.

[2] Z. Dong and G. Wu, "Research progress on durability of FRP bars reinforced concrete structures," China Civil Engineering Journal, vol. 52, no. 10, pp. 1-19, 2019.

[3] K.-S. Yeon, Y.-S. Choi, K.-K. Kim, and J. H. Yeon, "Flexural fatigue life analysis of unsaturated polyester-methyl methacrylate polymer concrete," Construction and Building Materials, vol. 140, pp. 336-343, 2017.

[4] M. J. Hashemi, M. Jamshidi, and J. H. Aghdam, "Investigating fracture mechanics and flexural properties of unsaturated polyester polymer concrete (UP-PC)," Construction and Building Materials, vol. 163, pp. 767-775, 2018.

[5] J. P. Gorninski, D. C. Dal Molin, and C. S. Kazmierczak, "Study of the modulus of elasticity of polymer concrete compounds and comparative assessment of polymer concrete 
and portland cement concrete," Cement and Concrete Research, vol. 34, no. 11, pp. 2091-2095, 2004.

[6] National Standard of Canada, "CSA S807-19:Specification for fibre-reinforced polymers," 2019.

[7] American Concrete Institute, "ACI 440.1R-15: guide for the design and construction of concrete reinforced with FRP bars," 2015.

[8] Q.-d. Hao, Y.-1. Wang, J.-1. Hou et al., "Experimental study ON bond behavior of GFRP ribbed rebars," Engineering Mechanics, vol. 25, no. 10, pp. 158-165, 2008.

[9] H. Zhang, F. Zhu, Li Sun et al., "Experimental study on bondslip behavior between FRP bars and concrete," Journal of Shenyang Jianzhu University (Natural Science), vol. 24, no. 6, pp. 989-992, 2008.

[10] D.-y. Gao and B. Brahim, "Bonding mechanism and calculating method for embedded length of fiber reinforced polymer rebars in concrete," Journal of Hydraulic Engineering, vol. 11, pp. 70-78, 2000.

[11] D.-y. Gao and B. Brahim, "Influential factors of bond properties between fiber reinforced polymer (FRP) rebars and concrete," Industrial Construction, vol. 31, no. 2, pp. 9-14, 2001.

[12] M. Baena, L. Torres, A. Turon, and C. Barris, "Experimental study of bond behaviour between concrete and FRP bars using a pull-out test," Composites Part B: Engineering, vol. 40, no. 8, pp. 784-797, 2009.

[13] A. Rolland, M. Quiertant, A. Khadour, S. Chataigner, K. Benzarti, and P. Argoul, "Experimental investigations on the bond behavior between concrete and FRP reinforcing bars," Construction and Building Materials, vol. 173, pp. 136-148, 2018.

[14] A. Veljkovic, V. Carvelli, M. Michal Haffke et al., "Concrete cover effect on the bond of GFRP bar and concrete under static loading," Composites Part B, vol. 124, pp. 40-53, 2018.

[15] R. Eligehausen, E. P. Popov, and V. V. Bertero, "Local bond stress-slip relationships of deformed bars under generalized excitations," Engineering Research Center, vol. 83, pp. 69-80, 1983.

[16] E. Cosenza, G. Manfredi, and R. Realfonzo, "Behavior and modeling of bond of FRP rebars to concrete," Journal of Composites for Construction, vol. 1, no. 2, pp. 40-51, 1997.

[17] L J Malvar, "Bond stress-slip characteristics of FRP rebars," Report: TR-2013-SHR, Naval Facilities Engineering Service Center, Port Hueneme, CA, USA, 1994.

[18] E. Cosenza, G. Manfredi, and R. Realfonzo, "Bond characteristics and anchorage length of FRP rebars," in Proceedings of the 2nd International Confernce on Advanced Composite Materials in Bridges and Structures, Montréal, Canada, August 1996.

[19] D. Gao, H. Zhu, and J. Xie, “The constitutive models for bond slip relation between FRP rebars and concrete," Industrial Construction, vol. 33, no. 7, pp. 41-43, 2003.

[20] C. Yand, S.-t. Yang, and D.-h. Qi, "Experimental study on the bond performance between BFRP bars and coral concrete," Engineering Mechanics, vol. 35, no. Supp 1, pp. 172-180, 2018.

[21] L. Wu, Y. Wang, L. Xie et al., "Study on bonding behavior between glass fiber reinforced polymer and engineered cementitious composite," Acta Materiae Compositae Sinica, vol. 37, no. 7, pp. 696-706, 2020.

[22] M. Baena, L. Torres, A. Turon, M. Llorens, and C. Barris, "Bond behaviour between recycled aggregate concrete and glass fibre reinforced polymer bars," Construction and Building Materials, vol. 106, pp. 449-460, 2016.
[23] C.-y. Wan, G.-x. Chen, L. Chen et al., "Study on the bond performance between BFRP bars and steam curing concrete," Fiber Reinforced Plastics/Composites, vol. 8, pp. 57-61, 2016.

[24] W.-d. Zhang, Z.-b. Wang, and W.-z. He, "Experimental study on bond behavior of GFRP rebars and rubberized concrete," Fiber Reinforced Plastics/Composites, vol. 8, pp. 71-74, 2015.

[25] S. Chen, H.-b. Lv, and L. Wang, "Constitutive model of bondslip relation between FRP bar and coral concrete," Journal of Guilin University of Technology, vol. 39, no. 1, pp. 107-113, 2019.

[26] H. Liu, J. Yang, and X. Wang, "Bond behavior between BFRP bar and recycled aggregate concrete reinforced with basalt fiber," Construction and Building Materials, vol. 135, pp. 477-483, 2017.

[27] Z.-Q. Dong, G. Wu, X.-L. Zhao et al., "Long-term bond durability of fiber-reinforced polymer bars embedded in seawater sea-sand concrete under ocean environments," Journal of Composites for Construction, vol. 22, no. 5, pp. 1-12, 2018.

[28] O. I. Németh, É. Lublóy, and G. Farkas, "Bond of reinforcement in polymer Concrete," Periodica Polytechnica Civil Engineering, vol. 58, no. 2, pp. 137-141, 2014.

[29] A. Douba, M. Genedy, E. N. Matteo, U. F. Kandil, J. Stormont, and M. M. Reda Taha, "The significance of nanoparticles on bond strength of polymer concrete to steel," International Journal of Adhesion and Adhesives, vol. 74, pp. 77-85, 2017.

[30] S. Solyom and L. B. György, "Bond of FRP bars with different surface characteristics," Construction and Building Materials, vol. 364, 2020. 